A A A

$A^{A} A^{A A}$
A A

\section{A A}

A

A $\quad$ A

Us $e \quad e \quad c \quad s \quad e \quad r \quad$ tf $e$

A

A

A

A A A
A

A A 


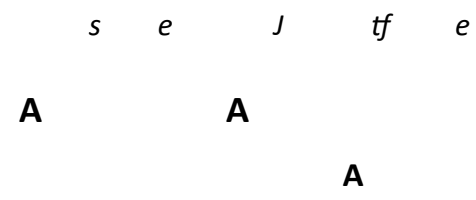

A

A 
$s e$ tf $e$

A

A 
$s e$ J tf $e$

A

A
Us $e$

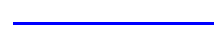


s

J tf

e

Us $e$

A

A 
$s \quad$ J tf $e$

Us $e$ e

- 
$s e$ tf $e$

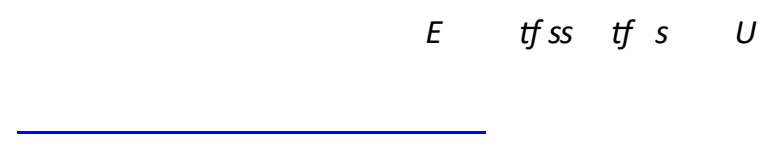

$-2$

tf $t f \quad e t f$ e

Us $e \quad e$

$s$

$s \quad t f$

$S$ 